\title{
El patrimonio fotográfico de México: una responsabilidad para los bibliotecólogos
}

\author{
Elke Köppen Pruebman \\ Centro de Investigaciones Interdisciplinarias en Ciencias y \\ Humanidades de la UNAM, 04510, México D .F., Tel: 56-23-40-33 \\ E-Mail: koppen@ servidor.unam.mx
}

\begin{abstract}
RESUMEN
Las imágenes creadas por los seres humanos a partir de su propia existencia deben entenderse como un bien cultural. Las imágenes fotográficas de ayer y hoy son así parte fundamental del patrimonio cultural de un pueblo, y su conservación, organización y difusión son tareas ineludibles para garantizar el acceso a la memoria colectiva. Los mayores retos frente a la enorme fragilidad del material que se añade a la complejidad de la imagen fotográfica como documento (que representa objetos o sucesos) y como objeto en sí, son conservar el soporte y descifrar el contenido.

México cuenta con un patrimonio fotográfico de enorme riqueza. Algunas colecciones han recibido el apoyo gubernamental, como el de Casasola, otras yacen en el olvido, condenadas a la desaparición.

El artículo concluye que los bibliotecólogos (que tienen presencia casi nula en las grandes fototecas) deberían tomar parte activa en todas estas tareas y propiciar una normatividad nacional que puede y debería derivar en un registro nacional del patrimonio fotográfico de México. Finalmente se ponen a discusión algunas propuestas.

Palabras Clave: Fotografías, Conservación de Documentos, Organización Documental, Patrimonio Documental.
\end{abstract}

\section{Mexico's Photographic Patrimony: A LIBRARIAN'S RESPONSIBILITY ELKE KÖPPEN-PRUEBMAN}

\begin{abstract}
ABST RACT :
The images created by human beings in relation with their own existence must be understood as a cultural possessión. The photographic images of yesterday and today are a fundamental part of the cultural patrimony of a people, and its conservation, organization and diffusion are unavoidable chores that guarantee the access to the colective memory. The greatest challenges which face the enormous fragility of the material immanent to the photographic image considered as a document
\end{abstract}

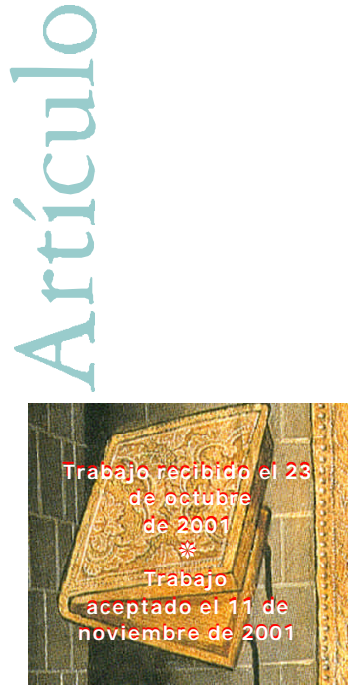


(representing objects and happenings) and as an object in itself, are to preserve the medium itself and to decipher its contents.

Mexico has a photographic patrimony of enormous value and fortunately some collections have received governmental support, like Casasola's, but others face oblivion. The paper states that librarians (whose presence is almost null in the great photo libraries) should take an active part in all these tasks and propitiate a national normativity which could and should give place to a national register for Mexico's photographic patrimony. Some proposals are put to discussion.

Key Words: Photographs, Documents Preservation, Documental Organization, Documental Heritage.

T odos "guardamos" fotografías. ¿Quién no tiene en casa fotografías de la familia, de los compañeros de escuela, de bodas, cumpleaños, bautizos y vacaciones en el mar? Las tenemos guardadas en cajas todas revueltas o en álbumes adheridas según algún orden. Y si somos muy minuciosos, las fotografías vienen acompañadas con maestría caligráfica de los datos de fecha, lugar, evento o alguna leyenda graciosa. Pero la fotografía privada encuentra entrada en los archivos sólo cuando se trata de gente o familias importantes, quienes donan o venden sus colecciones particulares aalguna institución que las pueda considerar de interés histórico. Las fotografías instantáneas (Polaroid) y las tomas de sorpresa (snaphdds) usualmente tampoco encuentran lugar en una colección, al menos que las tome alguien con tanto prestigio como, por ejemplo, el pintor oaxaqueño Francisco Toledo. No obstante, considerando lavocación comercial delafotografía nos encontramos frentea cantidades exorbitantes de imágenes sin trascendencia aparente.

Hablar de colecciones fotográficas nos lleva también a preguntar quiénes son los que producen fotografías y quiénes los que las guardan 0 archivan profesionalmente. Los fotógrafos profesionales compiten en la cantidad de imágenes producidas por los millones de fotógrafos aficionados. Los estudios fotográficos conservan los negativos tomados a sus clientes para una eventual reproducción y no es extraño que muchas colecciones históricas se compongan de estos acervos rescatados del olvido. Cuando los fotógrafos dedicados a la fotografía comercial y publicitaria o de viajes no tienen que cumplir con un pedido en particular, ofrecen en venta o renta sus fotografías a agencias especializadas. Las instituciones tienen a su servicio fotógrafos que registran bienes o actos oficiales. Los reporteros gráficos trabajan para periódicos que organizan sus propios acervos. Y no debemos olvidar las instituciones dedicadas a la investigación o docencia, que documentan sus especialidades disciplinarias con imágenes creadas ex profesoo recopiladas de otros entes. También los fotógrafos artistas - sin negar la creatividad de los profesionales anteriormente citados- guardan los negativos para una posterior reproducción, pero es posible también que terminen en museos 0 en manos de coleccionistas particulares con interés especial por la fotografía. Sin embargo la cantidad de fotografías que producen es 
asombrosa. La producción de cualquier pintor rara vez rebasa las trescientas a cuatrocientas obras, mientras que el archivo del fotógrafo consta de miles cuando no cientos de miles de negativos considerando que solamente una muy pequeña parte fue seleccionada para exponerse o publicarse.

Podemos suponer - aunque consideramos que la pérdida supera nuestra capacidad de imaginación- las innumerables piezas que se han perdido con el paso del tiempo por tratarse de un material tan frágil y perecedero si no recibe el merecido cuidado.

\section{LA FOTOGRAFÍA: MEMORIA IN DIVIDUAL Y COLECTIVA DE UN PUEBLO}

El siglo XX fue sin duda la centuria dominada por una cultura visual en donde la imagen compitió con la palabra escrita, proceso que previsiblemente se acrecentará aún más en el presente siglo. D e mero complemento del texto escrito, la imagen llegó a ser en muchos casos el centro de atención donde la palabra impresa (o hablada) complementó la imagen. La fotografía tiene que ver en eso. Su entrada triunfal a la prensa, su influencia en el ciney la televisión y su indiscutible poder en la publicidad, la convirtieron en un medio que ha marcado nuestra era.

Al igual que en el orden público, la fotografía se desarrolla en el ámbito privado e íntimo de las personas. Su gran aceptación se debe a la posibilidad de corresponder al deseo de captary aprehender el instante, de inmortalizar lo perecedero mediante una imagen que dé fe y perdure para la posteridad, que se inscribe en la debilidad de la humanidad por dejar vestigio de su existencia pasajera por este mundo. Ha adquirido también su merecido reconocimiento como expresión artística, y en calidad de documento visual juega un papel importante en la investigación científica y humanística al rebasar su utilidad como objeto ilustrado gráfico para convertirse en objeto de estudio de diversas disciplinas. Las redes electrónicas son hoy el ambienteidóneo para ofrecer un acceso instantáneo a todo este mundo inagotable de imágenes.

La proclamada "muerte de la fotografía" a causa de su creciente pérdida de materialidad y la consiguiente posibilidad de manipulación electrónica de imágenes, ${ }^{1}$ es otro asunto que invita a reflexionar sobre este medio tan popular. La potencialidad de las nuevas tecnologías nos plantea además la pregunta de si la digitalización resulta una panacea o presenta un peligro para la conservación de los materiales fotográficos tanto antiguos como contemporáneos.

Las imágenes creadas por los seres humanos a partir de su propia existencia pueden entenderse como un bien cultural. Las imágenes no se crean en el vacío, se encuentran insertas en un contexto cultural en el quese crean y el cual determina su uso

1 Hay quienes afirman que la fotografía digital ya no es fotografía en sentido estricto dado que carece de una capa fotosensible en la que se forme una imagen latente que tiene que ser químicamente tratada para hacerse visible. Asimismo la fotografía digital tiene como característica el hecho de que permite la manipulación deimágenes sin dejar rastro alguno de este acto y de la producción de imágenes simuladas; es decir, que no son reflejo de la "realidad" sino que constituyen una realidad virtual. 
y su significado. La importancia de las imágenes fotográficas, en lo que a herencia cultural se refiere, queda plenamente constatada en un documento elaborado por el Programa de la Memoria del Mundo de laUNE SCO, 2 preocupado por la preservación de documentos de todo tipo, dado que según dicho Programa tales imágenes contienen "la evidencia más significativa de los esfuerzos intelectuales y culturales dela humanidad". ${ }^{3}$ La UNESCO, en su preocupación por preservar la memoria colectiva, incluye al material fotográfico en igualdad de condiciones al lado de otros soportes como el papel y otros materiales tradicionales, soportes mecánicos, materiales magné ticos y medios ópticos. También toma en cuenta las publicaciones y los documentos electrónicos y hace referencia a la información virtual. En lo que se refiere a su preservación existen diferencias fundamentales y éstas no conciernen únicamente al material, su durabilidad y su estabilidad temporal. La diferencia es aún más significativa; daños causados a materiales distintos tienen consecuencias distintas:

El material impreso representa el pensamiento humano mediante el uso de un conjunto de símbolos. Una cierta cantidad de redundancia es intrínseca al habla y a la escritura. Se pueden suprimir letras, a veces hasta palabras, sin ningún detrimento a la comunicación. Un buen ejemplo son los escritos de las lenguas semíticas que generalmente no pueden representar a todas las vocales habladas. Pero aun textos complejos como los tratados filosóficos pueden ser comunicados por estas lenguas.

En contraste, el documento audiovisual constituye una representación analógica de un estado físico o evento: cada parte de un documento es así información. Mientras una mancha producida por hongos en un libro normalmente no obstaculiza la comprensión del texto, un daño comparable en una fotografía afectaría información y en una cinta magnética podría hacerla hasta irreproducible. Visto desde una perspectiva de la re dundancia, los documentos audio-visuales reclaman un grado mayor de protección y de seguridad que los materiales escritos. D atos digitales pue den sufrir daños similares. ${ }^{4}$

En tanto recurso informativo, la fotografía se ha mantenido en un lugar especial dada su capacidad técnica de dar una representación visualmente "fiel" de la realidad. ${ }^{5}$ Su gran potencial se encuentra en la posibilidad de fijar instantes, recortar la realidad, encuadrar lo decisivo, llamar la atención y, sobre todo, causar impacto y sentimientos. Su poder es aprovechado sin tregua por la publicidad, los medios (impresosy electrónicos) y la propaganda política, y su función didáctica es innegable.

2 Memoryoftheword Safegrardingthedbametaryheitage A giidetostandards, recommendedpradicesandrefe reneliteraturerdated to thepresevation ofdbouments of all kinds prepared by the International A dvisory Committee for the UNESCO Memory of the World Programme, Sub-Committee on Technology for the General Information Programme and UNISIST, United Nations Educational, Scientific and Cultural O rganization, [s.f.], consultado en

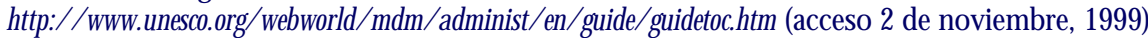

3 Ibidem

4 Ibidam

5 Fiel no significa necesariamente "objetivo". 


\section{Investigadón Biblidtedoóġav. 15 No. 31 julio/ diciembre de 2001}

México cuenta con una cultura visual riquísima. Las pinturas rupestres, el colorido de las pinturas prehispánicas, las piedras labradas con maestría, los códices que cuentan pictóricamente una historia, los paisajistas que retratan a la naturaleza y los muralistas que denuncian la subyugación de los pueblosy la explotación del hombre por el hombre, dan plenafe de esta afirmación. Lafotografía, otra expresión pictórica, ha tenido desde sus días pioneros un éxito rotundo en México. Dado que es un invento europeo y sus aparatos e implementos eran importadosy sumamente costosos, no es extraño que desde sus inicios la presencia de extranjeros haya sido notable. Pero ésta no es la única causa. Como escribe Carole Naggar en el libro Mexica Throughforegneges que recopila el trabajo fotográfico de extranjeros en México por 140 años:

Solamente Egipto ha atraído tantos fotógrafos como México en el siglo XIX. Pero en México (a diferencia de Egipto dondela mayoría de la fotografía contemporánea es tomada por turistas), esta fascinación todavía perdura; de hecho, hasido raro encontraralgún fotógrafo que no haya estado en México. ${ }^{6}$

México ha ejercido siempre una fuerte atracción para los viajeros y mentes abiertas y curiosas. Su fascinación por el país, su gente y su lucha por sobrevivir en la adversidad, se expresan en sus fotografías. Muchos estuvieron de paso, otros permanecieron por alguna temporada en el país y no pocos se quedaron. La historia de la fotografía estállena de viajeros, emigrantes y exiliados, y tampoco faltan los invasores. Estas aportaciones son parte sustancial de la fotografía mexicana. Hubo un encuentro fructífero con los magníficos fotógrafos nacionales. Un encuentro de miradas que le ha dejado un legado importante a la posteridad. ${ }^{7}$ México no solamente tiene un acervo rico en material fotográfico sino que también carga con una responsabilidad muy grande. Se trata de la enorme tarea de conservar la memoria colectiva de un pueblo plasmada en imágenes de sales plata. Ciertos acervos, como el de Casasola, han recibido el apoyo gubernamental; otros yacen en el olvido, condenados a la desaparición.

En México las instituciones a nivel nacional que tienen más responsabilidades asignadas a este respecto son el Instituto Nacional de Antropología e Historia y el Archivo $\mathrm{G}$ eneral de la Nación. Hay que destacar que los años sesenta resultaron un parteaguas para las colecciones fotográficas en México. Con la adquisición, en 1976, del Archivo Casasola por parte del Instituto Nacional de Antropología e Historia durante la presidencia de Luis Echeverríay la asignación de un espacio ex profesopara la colección en el ExConvento de San Francisco, en Pachuca, se abre un capítulo

6 Naggar, Carole, "Lafascinación del otro/ The fascination por the other", en Naggar, Caroley Fred Ritchin, Mexica Thrangfareigneged V istoporgosextranjeos 1850-1990, New Y ork: W.W. Norton, 1993, pp. 43-44.

7 Para una historia de la fotografía mexicana consulte el libro de O livier D ebroise, Fugamexicana Un reecridopor la fotografía en Méxica México: Consejo Nacional para la Cultura y las Artes (CNCA), 1998, $393 \mathrm{pp}$. 
nuevo para la conservación de la historia gráfica de México. En 1985, el Archivo Ge neral de la Nación se muda a sus nuevas instalaciones en Lecumberri, donde se crea el Centro de Información G ráfica del Archivo Histórico Central. Nuevamente el INAH toma la vanguardia al crear en 1993 el Sistema Nacional de Fototecas (SINAFO ) con la finalidad de normar, coordinar y supervisar las actividades de los archivos fotográficos que el INAH tiene bajo su custodia. ${ }^{8}$ Posteriormente se integran también fototecas al Sistema, que no pertenecen al INAH. En 1994 se inaugura el Museo de la Fotografía en las instalaciones de la Fototeca de Pachuca para documentar la historia de la fotografía y la G alería Nacho López abre un espacio para los fotógrafos contemporáneos.

El interés por las historias regionales, aunado a la búsqueda de la identidad inherente a los pueblos, abre el camino para el rescate de varias colecciones fotográficas regionales en el país, como lo demuestran los casos de Jiménez, en Juchitán; de Romualdo G arcía, en Guanajuato; de Sandoval-Lagrange, en Nuevo León, y delos Salmerón, en Guerrero.

Pero ¿cuántas fototecas hay en México? Es difícil encontrar la respuesta. Muchos archivos estatales y municipales cuentan en sus acervos con fotografías, pero no las tienen organizadas como sección o colección especial, resguardada y organizada con criterios propios y separada de otras colecciones, y caen así bajo el rubro de los que afirman: "también tenemos fotografías" que muchas veces se encuentran en condiciones poco adecuadas para ese material.

Un primer directorio que da cuenta a nivel nacional de colecciones fotográficas es la recopilación de Martha D avidson. ${ }^{9}$ É ste abarca un espectro más amplio que la fotografía al recopilar los acervos pictóricos en general, incluyendo imágenes como pinturas, dibujos, manuscritos ilustrados, estampas, grabados, litografías, serigrafías, mapas y fotografías. No podemos juzgar aquí el rigor de la investigación, pero sin duda es una fuente que ofrece un acercamiento valioso a la realidad mexicana. D esgraciadamente esta publicación se orientó hacia a un público norteamericano y nuncafuetraducida al español. A esto se añadeel hecho de que solamente cuatro bibliotecas en toda la UNAM cuentan con un solo ejemplar de este directorio. ${ }^{10}$

O tra fuente que reporta información sobre acervos fotográficos en México es el directorio de la empresa IBCON sobre centros de información, ${ }^{11}$ que nos ofrece el rubro de fototeca en los índices. Apenas en septiembre del 2000, en el marco de

8 Véase Casanova, Rosa, "Un sistema nacional de la fotografía”, Alquimia año 1, núm. 2, México, enero-abril de 1998, p. 41 y Bali, Jaime y Víctor Hugo Valencia, “A cervos fotográficos. Imágenes de la historia, historia de la fotografía. Sistema Nacional de Fototecas", Méxicoend Tiempo núm. 2, México, 1994, pp. 45-50.

9 D avidson, Martha etal. (eds.), Picurecdletions, Mexica A guidetopicuresarcesin theUnited Mexican States, Metuchen, New Jersey: Scarecrow, 1988, 292 pp.

10 Las bibliotecas del Instituto de Investigaciones Estéticas, de la Facultad de Filosofía y Letras, del Instituto de Investigaciones Históricas y del Centro de Estudios sobre la Universidad.

11 IBCON, Directorio de centros de información, México: IBCON, publicación anual. 
Primer Encuentro Nacional de Fototecas, organizado por el la Fototeca Nacional del INAH en Pachuca, se anuncia la elaboración de un tan necesitado directorio nacional, proyecto impulsado por el Centro de la Imagen, dependiente del Consejo Nacional de la Cultura y las Artes.

\section{ARCHIVOS FOTOGRÁFICOSY NORMALIZACIÓN}

¿Qué hace tan especial a una imagen fotográfica? Una imagen fotográfica no es un documento cualquiera. Su materialidad como artefacto extremadamente frágil físicay químicamente hablando, su polisemia potencial en lo que se refiere a su contenido pictórico y su dualidad como documento-objeto, la hacen acreditable a un tratamiento muy especial.

En los archivos fotográficos, las fotografías deben ser tratadas como documentos que contienen información visual, sin importar el género involucrado. Según Estelle Jussim, ${ }^{12}$ el término información visual "representalaidea 'del contenido visual de los documentos' (no importando el medio) y menos la del proceso que implicala comunicación en toda su complejidad. La información visual debería ser correctamente definida como subconjunto de la comunicación visual porque se refiere al documento visual en sí mismo más que a intenciones, interacciones sociales u otras variables de un proceso más amplio."13 Esta definición queda corta hoy en día frente al reconocimiento que ha recibido la fotografía como lenguaje propio quedispone de sus códigos inherentes. Hay que saber leerla fotografía, ${ }^{14}$ porque no solamente es un subconjunto de la comunicación visual, sino que contiene intenciones obvias y ocultas, interpretaciones de la realidad y mensajes. Del Valle Gastaminza considera "la fotografía como un documento integrado por soporte e información transmisor de un mensaje codificado que exige un esfuerzo decodificadorpor parte del destinatario." 15 Conservar el soporte y descrifrar el significado es el mayor reto.

Para que el material fotográfico en sí y, en su caso, la información complementaria alaimagen sea organizado de manera coherentey consistente, para que sea accesiblee intercambiable y para que se conserve, se necesitan normas que rijan el manejo de una colección fotográfica. La toma de decisiones equivocadas o arbitrarias en materia de normalización puede tener consecuencias graves, tanto para la institución que ofrece un producto o servicio, como para el cliente o usuario que recurre a la búsqueda de información. Las decisiones acerca de qué normas aplicar deben ser razonadas y, en el mejor de los casos, surgir de una reflexión colectiva de profesionales que toman en cuenta los contextos local, regional e internacional e incluyen una visión a futuro.

12 Jussim, Estelle, "The research uses of visual información", Library Trends vol. 25, núm. 4, abril de 1977, pp. 763-778.

13 Ibidam p. 763.

14 Es interesante el libro de Roberto Aparici y Agustín García-Mantilla, Leedra deimágnes Madrid: Ediciones delaTorre, 1998, 120 pp., el cual además ofrece una guía prácticadeaplicación educativa.

15 Valle G astaminza, Félix del, "Dimensión documental de la fotografía", en Félix del Valle Gastaminza (ed.), Manual dedbometaciónfotogááica, Madrid: Editorial Síntesis, 1999, p. 13. 
En lo que se refiere al ambiente de la información y la documentación encontramos normas para la presentación de documentos, del control bibliográfico, de la transliteración, de la terminología, de la descripción del contenido, de la realización de catálogos y ficheros, de los locales y equipamientos, de la reproducción, de la informática y de la telemática, de la gestión y de los sistemas de información. ${ }^{16}$

La conservación es una actividad fundamental en el manejo de colecciones fotográficas y no solamente se requiere para el material histórico sino también para material contemporáneo. G arantizar el acceso intelectual al contenido pictórico es otro desafío. También es imprescindible afrontar la tentación de reducir la fotografía a una categoría excluyente (arte, mera fotografía, documentación, prueba, ilustración, etcétera) y tratarla como documento (que representa objetos o sucesos) y como objeto en sí. Todas estas particularidades aumentan la dificultad y complejidad que representa en sí la organización, el almacenamiento y la recuperación de información.

¿Q uién se ha preocupado principalmente por la normalización de todas estas tareas? La industria fotográfica, en primera instancia, requirió de una normalización rigurosa. Esto se refleja en la existencia, desde 1947, del Comité Técnico 42 de la ISO , especialmente dedicado a la fotografía por lo que se refiere a la elaboración de normas técnicas. El Comité trabaja en estrecha colaboración con el American National Standards Institute (ANSI) y la Photographic and Imaging Manufacturers Association (PIMA). ${ }^{17}$ Muestra de los avances logrados son la uniformización actual de las dimensiones de los rollos y las placas fotográficas, de los códigos de velocidad que miden la sensibilidad a laluz de las películas y de los diferentes procesos de revelado, por aludir sólo a algunos. D e las normas técnicas relativas al material fotográfico - sus propiedades físicas, los procesos químicos y las condiciones de almacenaje requeridos- se derivan las normas aplicables a la conservación de colecciones fotográficas en las fototecas. Una institución de vanguardia es el Rochester Image Permanence Institute que dedica sus esfuerzos a la conservación fotográfica como disciplina científica y que forma profesionales altamente calificados.

En lo que se refiere a la normalización para el acceso intelectual a las colecciones visuales ${ }^{18}$, los más preocupados fueron los bibliotecarios, archivistas y curadores de

16 Véase G uinchat, Claire y Michel Menou, Introduccóngeneal alasdeniasyténicasdelainformacónydo ametacón (segunda edición corregida y aumentada por Marie-France Blanquet), Madrid: CIND O C(CSIC)/ UNESCO, 1990, pp. 447-448.

17 ISO / TC42 se dedica a la normalización de definiciones, dimensiones y la práctica recomendada en el campo de la fotografía, a los métodos para poner a pruebay clasificar las características del comportamiento de materiales y dispositivos fotográficos, así como a los métodos, materiales y procesos usados para la reproducción fotográfica de documentos. Para realizar su labor cuenta con varios grupos de trabajo (cfr. http/ / unwpimant/ standard/ te42.htm)y su dedicación se amplía hoy también al ambiente digital así como el reciclaje. Consulte también la página de PIMA http/ / unwpimant/ standardd TC.hm.

18 Conceptualmente ubicamos a las fotografías almacenadas en acervos en el contexto de las llamadas colecciones visuales. Nancy Schelby Schuller, vinculada a la Visual Resources Association (VRA), limita las colecciones visuales a material fotográfico: "El término decciónisual se ha desarrollado como descripción paralo que anteriormente se habíallamado biblioteca o colección foto- 
transparencias en instituciones ligadas a la historia y documentación del arte, especialmente en universidades y museos. G lyn Sudcliffe ${ }^{19}$ nos relata el problema de los curadores de transparencias que no se sintieron suficientemente representados en su quehacer y sus necesidades concretas por el gremio bibliotecario, y cómo eso los llevó a promover una organización propia. En 1982 se creó, como una entidad profesional aparte, laVisual Resources Association (VRA). También laArt Libraries Society of North America (ARLIS/ NA) se ve en la necesidad de crear una Visual Resources Division.

Lo que es indiscutible es que las imágenes requieren de otros procedimientos, de otro tratamiento diferente al que se les da a libros, revistas u otros impresos. La inclusión de imágenes como parte significativa en el ámbito de la información y la documentación y su incorporación a los acervos, dio origen a la demanda de profesionales que enfrentaron estas nuevas necesidades. Las variadas denominaciones profesionales como artlibranians picurelibranians imagelibranians audiovisual libraians visual reaurceslibranians, photolibranianso sidearatarsdan cuenta de esta necesidad de especialistas. Las nuevas tecnologías de la información aplicadas al mundo de las imágenes (digitalización, almacenamiento, recuperación, etcétera) han acrecentado aún más la presión sobre la especialización requerida. Para corresponder a esta nue va demanda, ARLIS/ NA elaboró un perfil que debe cumplir un profesional de colecciones visuales ${ }^{20} \mathrm{y}$ que toma en consideración las particularidades que exige este trabajo, el cual merece un rango y un estatus igual al de los otros profesionales con los mismos niveles de calificación académica. El documento enfatiza:

Elacceso intelectual alainformación, sin importar su formato, es la pauta para la administración eficiente de una colección. Para poder proporcio-

gráfica o de transparencias. Las razones más plausibles para esta transición corresponden a la creciente variedad de formatos visuales que se coleccionan hoy en día y buscan evitarla impresión deque una colección visual provee el mismo tipo de acceso y servicio que unabiblioteca[delibros]. Una colección visual es cualquier organización o unidad que tiene como su función primordial la colección de imágenes fotográficas con propósitos de investigación, docencia, o documentación histórica." (Schuller, Nancy Shelby, Managenettforvisal resancescolletions Englewood, Colorado: Libraries Unlimited, 2a. ed., 1989, p. ix.) O tros, como Betty Jo Irvine, vinculada a la Art Libraries Society of North America (ARLIS/ NA) incluye, transparencias, fotografías, videos, microfichas, películas y otros medios (Irivine, Bety Jo (ed.), Failitiesstandardsforartlibraniesandvisual resarces $\Theta$ leetions Englewood, Colorado: ArtLibraries Society of Noth America/ Libraries Limited, 1991, p. 57). Lo que en realidad importa es que una colección visual consiste en un acervo de imágenes cuya su función primordial (y estas imágenes pueden encontrar su morada en museos, bibliotecas, archivos, instituciones culturales, educativas y de investigación, empresas, organizaciones gubernamentales, etc.) puede constituir propósitos de investigación, docencia o documentación.

19 Sudcliffe, Glyn, Slidecdlection managenentinlibraiesandinformation units Hampshire and Vermont: Gower, 1995, pp. 33-37.

20 ARLIS/ NA and VRA, Criteioparalacontratacoónyretenióndeprefeicinalesdereansosvisuales consultado en http/ / unwrarlismaag publications citeiasphtml (acceso 22 de febrero, 2000)

El grupo de trabajo de Art Libraries Society of North America y la Visual Resources Association que se dedica a los tópicos relacionados con profesionales que trabajan colecciones visuales fue creado en 1991. Se está elaborando un reporte más extenso que se publicarábajo el nombre Guide lines for theV isul Resarces Profession 
nar este acceso intelectual, se requiere un conocimiento profundo sobre la materia, técnicas de investigación, experiencia administrativa, habilidad de enseñar y pericia en tecnologías avanzadas. ${ }^{21}$

Para hacerse cargo de una colección visual, se afirma, es muy recomendable tener una formación académica, preferentemente de posgrado, en el área temática de la colección así como contar con estudios complementarios en una disciplina como historia del arte y de administración de información (bibliotecología o ciencias de la computación), dado que a "diferencia de los bibliotecarios, archivistas o conservadores, que son casi siempre especialistas dentro de grandes unidades, los profesionales de la información visual participan activamente en el amplio espectro de responsabilidades intelectuales, administrativas y técnicas asociadas con sus colecciones." 22 ¿Estamos preparados en México para tales exigencias y responsabilidades?

\section{ASPECT OS NORMATIVOSEN FOTOTECAS MEXICANAS: CONCLUSIONES DE UNA IN VEST IGACIÓN}

En un estudio comparativo sobre aspectos normativos en fototecas mexicanas 23 analizamos las prácticas declaradas en materia de normalización de nueve fototecas seleccionadas para tal fin. ${ }^{24}$ Lejos de pretender ser una encuesta representativa, se

21 Ibidem

22 Ilidem

23 Köppen, Elke, Aspetosnomativosencdecionesisuales unestudiocomparativodefotdeasmexicanas Tesis de Maestría en Bibliotecología, México, Facultad de Filosofíay Letras, UNAM, 2001. Las entrevistas se realizaron en su gran mayoría en el año de 1999.

24 Antes de emprender la investigación se realizó una visita exploratoria a la Fototeca de Pachuca. Para seleccionar las fototecas se tomaron en cuenta las recomendaciones del Sistema Nacional de Fototecas (SINAFO) y se consultaron los directorios disponibles. Conviene aclarar que existieron limitaciones debido a que no se contó con financiamiento para realizar viajes, pero se visitaron fototecas no solamente en la Ciudad de México, sino también en Hidalgo, Guanajuato, Puebla y Nuevo León:

La Fototeca del INAH en Pachuca, también llamada Fototeca Nacional, es una institución creada ex prefesopara albergar los fondos fotográficos producidos en casi 70 años por las tres generaciones defotoreporteros de la familia Casasola. Este acervo que es fundamental para la historia gráfica del país, junto con los demás fondos integrados posteriormente, lo convierte en la fototeca más importante de México.

El Archivo G eneral de la Nación, institución responsable del resguardo de los documentos valiosos para el país, dispone en su Archivo Histórico de millones de fotografías, sobre todo negativos. Entre sus colecciones, que destacan por su gran riqueza, se encuentran las imágenes producidas por los hermanos Mayo.

El Archivo Fotográfico "Manuel Toussaint" del Instituto de Investigaciones Estéticas de la UNAM es una institución especializada en la documentación del arte y de la aquitectura y cuenta además con colecciones de gran valor artístico.

La Fototeca Culhuacán del INAH fue la primera entidad que recibía como depositaria la producción de imágenes de los fotógrafos del Instituto, Cuenta con una colección que documenta a los monumentos históricos de México. Forma parte del SINAFO.

El D epartamento de Información y D ocumentación de la Cultura Audiovisual de la Benemérita Universidad Autónoma de Puebla fue escogido para participar en la muestra porque tiene en su poder una colección valiosa de sillsde cine que les vendió el escritor Paco Ignacio Taibo. 
optó por un muestreo no probabilístico de tipo selectivo en el que se analizaron casos concretos a profundidad que nos permitieran acercarnos a un panorama más amplio, pero sobre todo proveernos de datos relevantes para el estudio.

La Fototeca del INAH en Pachuca no es en vano llamada también Fototeca Nacional, pues además de las tareas cotidianas de organización y conservación de los materiales guardados allí, tiene encomendado, como centro operativo del Sistema Nacional de Fototecas (SINAFO), la elaboración de propuestas de normalización en lo que a catalogación y conservación se refiere, y su personal presta asesorías alasfototecas del SINAFO y por convenio a otras instituciones que así lo solicitan. La ciudad de Pachuca tiene la ventaja de contar con condiciones climáticas bastante favorables para la conservación de material fotográfico y el edificio colonial fue adaptado para albergar lafototeca. Q uien menos atención ha merecido es, a mi parecer, el usuario que acude a consultar los fondos. Se aceptan por día solamente a tres investigadores a quienes se les dedican, eso sí, toda las atenciones requeridas por aproximadamente dos horas. O tro factor que apoya esta afirmación es el hecho de que existen únicamente dos computadoras destinadas a la consulta, cargadas cada una con bases de datos distintas. Con la instalación de un módulo de consulta en la Ciudad de México, se ha mitigado un poco esta situación, pero no es suficiente.

Algo muy distinto ocurre con el Archivo G eneral dela Nación, dondela consulta se realiza sin previa cita y donde los investigadores trabajan por su cuenta sin mayor asesoría. El AGN concentra millones de fotografías en su Centro de Información Gráfica y su personal está al cargo también de otros materiales gráficos como mapas, ilustraciones, videos y audiocintas. El personal adscrito al Centro está ampliamente rebasado en el manejo de tal cantidad de imágenes, a las cuales la institución no les dedicalos recursos humanos y económicos suficientes. No sorprende así que, por ejemplo, se presten a los investigadores cajas con negativos sin mayor supervisión. La catalogación de las imágenes es precaria y no se sigue una normalización, dado que cada colección tiene su propia forma de registro. La bóveda de seguridad se mantiene solamente a una temperatura de $20^{\circ} \mathrm{C}$ y la humedad relativa al $60 \%$ y no

El Centro de D ocumentación e Información Ferroviaria, dependiente del Museo Nacional de los Ferrocarriles Mexicanos, cuenta con una colección única sobre los ferrocarriles del país tratándose sobre todo de fotografía de registro y donaciones recibidas de viejos ferrocarrileros.

El Centro de Estudios de Historia de México, dependiente de una empresa privada, Condumex, posee un archivo histórico formado por colecciones de particulares adquiridos por el Centro o re cibidos en donación. Las fotografías, en su mayoría copias impresas, forman parte integral de los documentos. Su biblioteca y su archivo histórico son muy frecuentados por los estudiosos de la historia mexicana.

La Fototeca Romualdo G arcía se constituyó con las fotografías de un antiguo estudio fotográfico derenombre en la ciudad de Guanajuato. Pertenece al Museo Regional del estado y foma parte del SINAFO.

La Colección Sandoval-Lagrange reúne fotografías de estudio de dos fotógrafos regiomontanos pioneros de este oficio y fue adquirida por el Instituto Tecnológico de Estudios Superiores de Monterrey (ITE SM). Además, por su valor para la historia regional, nos interesó el tratamiento que se le da en una institución educativa privada de tanto prestigio como es el ITESM. 
existe separación entre las películas de nitrocelulosa y otros materiales fotográficos. Por fortuna se contrató una asesoría externa de especialistas altamente calificados en conservación fotográfica para que realizara un diagnóstico de la colección en los meses de febrero a noviembre de 2000. Faltará acatar las recomendaciones de estos asesores y destinar recursos extraordinarios a la conservación y organización, incluyendo, sin duda, la contratación de más personal calificado de manera permanente para asegurar la conservación y consultade tan valioso legado histórico y artístico.

ElArchivo Fotográfico "Manuel Toussaint" del Instituto de Investigaciones Estéticas de la UNAM fue la única fototeca que afirmó contar con recursos económicos suficientes. Cuenta con áreas bien definidas para las diferentes tareas y es notorio que el espacio fue diseñado desde el principo para servir como archivo fotográfico, aunque ya se está evidenciando la falta de lugar para expansión. Vista en conjunto, esta fototeca es muy especial no solamente por su misión tan definida de servir a una comunidad académica en sus labores de investigación y docencia, sino también por su crecimiento anual tan significativo, para lo que cuenta con bastantes recursos humanos, sobre todo del área de especialidad disciplinaria en la que está inserta. Como consecuencia de la huelga de la UNAM hubo casi cinco meses sin acceso al acervo, que se quedó sin ambiente controlado por el corte de electricidad. La prioridad será por lo pronto realizar labores de monitoreo de la colección y la restauración, en su caso, del material dañado.

LaFototecaCulhuacán estaba a punto de cambiarse ainstalaciones nuevas con lo que superará las graves deficiencias que ha sufrido en el aspecto ambiental. Pero falta trabajar también en la cuestión de la catalogación que no tiene puntos de contacto con las propuestas de normalización del SINAFO, al que pertenece. Hace poco tiempo que se envió personal con amplia experiencia adquirida en la Fototeca de $\mathrm{Pa}$ chucaa la Fototeca Culhuacán para hacerse cargo del acervo y mejorar su condición.

La fototeca del DID CAV fue incluida en este estudio por la valiosa colección que tiene de stillsde cine de los años cuarenta, cincuenta y sesenta. Fue sorprendente encontrar que esta colección no está inventariada ni catalogada. Como resguardadora de la fotografía oficial la fototeca cumple su función de servir a la institución, pero casi nunca acuden investigadores a consultar el acervo. Las condiciones ambientales podrían ser mucho mejores, pero la mayor dedicación gira alrededor de fotografías contemporáneas a pesar de que cuenta con material antiguo, aunque no numeroso. Esta fototeca es un buen ejemplo para los casos donde los fondos, aceptados por donación o adquiridos, no concuerdan con su misión principal. Esto produce que la colección quede en el olvido a pesar de su riqueza, porque siempre otras actividades serán prioritarias.

Algo similar ocurre con la Colección Sandoval-Lagrange del Instituto Tecnológico de Estudios Superiores de Monterrey. Fue adquirida en 1966 y desde esa fecha no se ha realizado gran cosa. Las piezas siguen en sus envolturas originales, guardadas en cajas en un cubículo del Centro de Información-Biblioteca (CIB) en condiciones ambientales queno garantizan su conservación alargo plazo. La colección ocupa un lugar 
marginal en el CIB y éste no cuenta con personal propio y especializado. El acceso a la colección está limitado no sólo por la falta de catalogación, y su utilidad se restringe a ser usado en exposicionesy publicaciones delainstitución. Existe un proyecto de digitalización muy ambicioso y publicitado pero requiere de muchos recursos. Este ejemplo ilustra el hecho de que la universidad privada no tiene como prioridad la conservación del patrimonio cultural, aunque quizá sí un gran interés por la explotación económica de la memoria colectiva.

Sucede lo contrario en la Fototeca "Romualdo G arcía”, adscrita al Museo Regional de $\mathrm{G}$ uanajuato, la que aporta su material fotográfico a la documentación de la historia regional. Lo notorio de este caso es que la fototeca como tal no cuenta con una cabeza organizativa, ya que es el Director del Museo quien funge como tal y quien incide en el trabajo de las dos responsables de área (de reciente ingreso) y del fotógrafo, único personal con que cuenta la fototeca.

El acervo fotográfico del Centro de D ocumentación e Información Ferroviaria se encontraba localizado antes en un vagón de ferrocarril en condiciones ambientales deplorables. A hora se halla en instalaciones reducidas pero en las que dispone de una bóveda con ambiente controlado para la conservación del material fotográfico. La fototeca cuenta únicamente con una persona que se ocupa de todo y solamente personal de servicio social la auxilia en las labores. Su capacitación la lleva a cabo la misma responsable, pero por tratarse de alguien que presta sus servicios temporalmente, su adquisición de conocimientos no es acumulativa.

Las fotografías del acervo histórico del Centro de Estudios de Historia de MéxicoCondumex son un ejemplo de aquellas entidades en las queel material fotográfico forma parteintegral de los documentos archivados. Aunqueno se trata denegativos también las impresiones requieren de condiciones de conservación específicas; pero lo más importante me parece el acceso a ellas. La guía que reporta los fondos reguardados en el archivo histórico no especifica el contenido de las fotografías y nos indica únicamente la cantidad del conjunto. Podríamos afirmar que el material visual que es organizado solamente para acompañaralos documentos es concebido más como historiailustrada que como historia gráfica, concepto que le asigna un valor muy diferente a la fotografía como medio de expresión y representación propio. Esta afirmación se ve reforzada por el hecho de que la colección fotográfica más grande, la colección Handcock sobre sitios arqueológicos, no está ni inventariada ni catalogada.

Sin duda las fototecas con mejores niveles de normalización son la Fototeca del INAH en Pachuca y el Archivo Fotográfico "Manuel Toussaint" del Instituto de Investigaciones Estéticas de la UNAM. Ambas tienen una organización interna muy compleja y cuentan con responsables por área, aunque éstas están definidas de manera muy distinta en cada caso. Las colecciones fotográficas con menor nivel normativo son las del Centro de Información G ráfica del AGN, del Archivo Histórico del Centro de Estudios de Historia de México-Condumex y la Colección Sandoval-Lagrange; instituciones que comparten áreas y personal, sin que esto se declare manifiestamente como causa de sus deficiencias. Sin embargo al no 
contar con una organización independiente, como lo requiere el material fotográfi$\mathrm{co}$, las colecciones fotográficas pueden quedar atrapadas en un círculo vicioso de ser propensas a no recibir el apoyo institucional necesario, de no contar con personal especializado y con la experiencia en el tratamiento intelectual y físico de materiales fotográficos, y de que el personal tampoco reciba esta capacitación constante y que no se busque la cooperación con otras fototecas.

$\mathrm{Si}$ en la muestra se hubieran incluido archivos municipales o estatales el panorama general hubiera sido más preocupante. Aun así, podemos deducir cuáles son los problemas generales que comparten muchísmas fototecas del país: la falta de recursos materiales y humanos. Esto se traduce en inventarios incompletos, una catalogación incompleta, una normalización precaria, condiciones de conservación deficientes que ponen en peligro la supervivencia de la colección a largo plazo, y sueldos bajos y la falta de capacitación del personal.

Pero tenemos que resaltar los esfuerzos de la gente comprometida con la Fototeca Nacional del INAH y el Sistema Nacional de Fototecas (SINAFO) y su búsqueda de una propuesta mexicana a los desafíos planteados. Su experiencia acumulada es aprovechada en la prestación de asesorías a las fototecas solicitantes y se plasma en la publicación de dos manuales, ${ }^{25}$ (uno de conservación y otro de catalogación) que comentan la normatividad propuesta para las fototecas pertenecientes al SINAFO . Pero también tenemos que comentrar algunas limitaciones. Por ser parte de una institución gubernamental la Fototeca de Pachuca se (con)funde con el SINAFO porque se inserta en una estructura burocrática ${ }^{26}$ que a su vez es vulnerable a cambios sexenales y enroques de funcionarios dentro de la administración pública. Pero es más importante señalar que en lo que concierne a su función de instancianormalizadora, a nivel nacional no se ha podido rebasar del todo el ambiente de la propia institución, el INAH, e integrar en mayor medida archivos estatales o municipales, acervos de material contemporáneo y colecciones que están en manos privadas. La propuesta de catalogación es influida por la visión de historiadores y antropólogos (raro sería que no fuera así), pero esto deja un poco al margen la imagen fotográfica en su faceta de lenguaje gráfico propio, como forma de reproducción de obras artísticas o como arte mismo (posición que predomina en las propuestas de VRA y ARLIS/ NA). Indudablemente hay que tomar en cuenta las aportaciones y la experiencia acumulada en la Fototeca de Pachuca, pero para lograr una normalización aceptada y concordada en una acción y reflexión colectiva para todo el patrimonio fotográfico de México quizá lo recomendable sería promover la creación de redes de fototecas afines e iniciar discusiones acerca de problemas comunes y prácticas normativas, así como compartir recursos y cooperar en la adquisición de equipo e implementos

25 Valdés Marín, Juan Carlos, Manual deconæavadónfotogáfica. Guíadeidantificadón etabilizacoónyrestaur racóndeprososfotogáficosdelossigosXIX yXX, México: INAH, 1997, 146 pp. (Colección Alquimia) así como Barra Moulain, Paula e Ignacio Gutiérrez Ruvalcaba, Nomascatalogáficasdd Sistema Na donal deFotdecas da INAH (manual ténico), México: INAH, 2000 (Colección Alquimia).

26 Coordinación Nacional de Difusión, Dirección del SINAFO, Subdirección de Fototeca 
para lograr un precio mejor. También podrían aportarse las experiencias y descubrimientos a la discusión para construir una normalización nacional que sirva no sólo para conservar sino para integrar un catálogo colectivo y un registro nacional del patrimonio fotográfico mexicano.

La experienciay el profesionalismo de los bibliotecólogos podría aportar mucho en esta gran tarea. ¿Pero tienen los bibliotecarios suficiente conciencia acerca del valor y la fragilidad del material fotográfico, y tienen suficientes conocimientos como para tomar las decisiones adecuadas en su manejo si se topan con este material en sus acervos? La casi nula presencia de bibliotecarios o archivistas en las fototecas estudiadas ${ }^{27}$ nos debería alertar sobre su formación. A todas luces no es suficiente limitar la enseñanza a la aplicación del capítulo 8 de las Reglas de Catalogación Angloamericanas, o abarcar las fotografías sólo como "auxiliares audiovisuales" en un curso donde se enseña prioritariamente, si no exclusivamente, el uso de materiales audivisuales para apoyar las actividades de difusión de las bibliotecas. Nos parece re comendable incluir en el plan de estudios de la licenciatura un curso obligatorio sobre colecciones visuales parecido al de bibliotecas especializadas, que introduzca el

27 Entre las 76 personas registradas encontramos siete historiadores, doce historiadores del arte, un biólogo un químico, un físico, tres científicos sociales, tres diseñadores gráficos, una persona con formación en letras, un archivista técnico, tres personas con estudios comerciales, trece fotógrafos, un trabajador social, un ingeniero industrial, un ingeniero en sistemas, un filósofo, cinco personas con estudios de computación, un maestro de educación física, un conservador, quince personas con bachillerato terminado (de los cuales siete recibieron una capacitación de dos meses de catalogación y otros siete tomaron cursos de conservación y restauración fotográfica) y cuatro capturistas.

Más interesante quelas cantidades totales es la distribución poráreas. Las únicasáreas donde existe un perfil técnico/ profesional claro es en el área de reproducción, dondelaboran mayoritariamente fotógrafos y, como es de esperarse, en el área de cómputo. En las áreas restantes existe una variedad inmensa en cuanto a la formación académica antecedente.

D ado que las fototecas y sus áreas no están organizadas de igual manera en las distintas instituciones, no es posible hacer una comparación rigurosa. Sin embargo es notorio que entre las personas con responsabilidades de tipo general sobre las colecciones fotográficas predominan los historiadores: seis historiadores/ historiadores del arte son directivos de las fototecas o encargados de las colecciones y diez historiadores del arte trabajan en la fototeca del Instituto deI Investigaciones Estéticas, dado que las responsabilidades se definen por especialidades temáticas y la asignación de fondos concretos y no por labores espeć́ficas. La evidente presencia de historiadores (diecinueve, incluidos los historiadores del arte) en los archivos no sejustifica por el simple hecho de tratarse en muchos casos de acervos históricos o especializados en la documentación del arte. Para el análisis decontenido de las imágenes, esto puede ser muy válido, pero no es así para las propuestas de organización, almacenamiento y recuperación de la información gráfica. Q uienes deberían tener inserción en ello, los bibliotecólogos y archivistas, tienen una presencia ínfima en este medio (un archivista técnico en el Archivo General de la Nación). En Pachuca se optó por formar técnicos propios que se seleccionan entre aspirantes con bachillerato terminado para tareas de catalogación y conservación, las cuales realizan bajo la supervisión de los coordinadores deárea. En lo que se re fiere a su formación académica antecedente, entre los responsables de tareas de catalogación encontramos una socióloga y una historiadora, y entre los responsables de conservación fotográfica, una diseñadora gráfica y una historiadora.

Con estos datos se puede confirmar que los fototecarios se forman en las fototecas. Ninguna institución de educación técnica o superior se hace cargo de esta tarea. 
cuidado tan distinto que implica este tipo de material, que enfatice su importancia dentro del patrimonio cultural de un pueblo, y que proporcione los conocimientos básicos para preservarlo así como para conocer las fuentes donde se pueden consultar las normas básicas que rigen su manejo y permanente actualización. Un curso más especializado podría darse a nivel de postgrado, donde el alumno aprenda no solamente a organizar colecciones sino también a identificar procesos y formatos fotográficos y sus posibles deterioros para poder elaborar políticas generales de conservación con base en las normas vigentes. Solamente así los bibliotecólogos tendrán la posibilidad de participar en la lucha por preservar el patrimonio cultural y de incidir en la elaboración de proyectos de ley y en la normalización de todas las tareas de control documental que pueden y deberían derivar en un registro nacional del patrimonio fotográfico de México.

Las tareas específicas de conservación y restauración requieren necesariamente de personal altamente especializado en un campo disciplinario emergente, como se reconoce recientemente en la conservación fotográfica. Para atender a esta necesidad, a nivel curricular, ya se dieron los primeros pasos al introducir un curso específico en la Escuela Nacional de Conservación, Restauración y Museografía del INAH, y la Academia de San Carlos anunció su primer curso para el semestre 2000-2, pero falta mucho camino por andar para instalarla como especialidad reconocida.

Paralaformación de profesionales delainformación visual seríaideal instaurar una especialización interdisciplinaria a nivel de postgrado (de cooperación interinstitucional) que cubra todas las áreas del conocimiento involucradas y que convoque a profesionales de varias disciplinas para aprovechar la riqueza de sus conocimientos y experiencias. Sin embargo poco sentido tendrá formar gente tan altamente calificada si las instituciones no toman conciencia de que cubren una necesidad real y ofrecen incorporarlos con remuneraciones que correspondan a su calificación. Mientras tanto hay que seguir trabajando en todos los niveles existentes, abrir nuevos caminos y formar técnicos y profesionales bien preparados en todos los campos.

\section{ANEXO: PROPUEST AS A DISCU SIÓN}

Para aportar elementos a la discusión colectiva acerca de la construcción de una normalización nacional del patrimonio fotográfico mexicano he aquí algunas propuestas concretas producto tanto de las reflexiones surgidas a partir de la investigación que realizamos como de la lectura de literatura especializada sobre el tema.

\section{Propuesta 1: \\ Secuencia de actividades según prioridades}

D ado que las fototecas en nuestro país disponen normalmente de recursos limitados es importante partir de una política general de prioridades que puede formularse de esta manera:

1. Conservación de primer nivel (para que la colección no se pierda) 
2. Inventario (para saber qué se tiene)

3. Difusión (para promover su consulta y recibir recursos)

4. Catalogación de primer nivel (para tener acceso)

5. Conservación avanzada

6. Catalogación avanzada

O tras actividades:

* Digitalización (Si hay recursos, puede realizarse simultáneamente con el inventario para aprovechar la manipulación de las piezas y apoyar la difusión; si no los hay se realiza después de la catalogación de primer nivel y la conservación avanzada para digitalizar piezas limpias, estabilizadas y catalogadas porque sirve para generar bases de datos. No debe entenderse como forma de conservación).

* Investigación (entra después del inventario, pero se podría involucrar a la gente en este proceso, previa instrucción sobre el manejo preventivo del material).

\section{Propuesta 2:}

\section{C onservación de primer nivel}

D escuidar la conservación pone en peligro la supervivencia de la colección. Por esto hay que declarar como prioridad absoluta, si se tienen pocos recursos, destinarlos a guardar las fotografías en un ambiente lo más frío posible y suficientemente seco, procurando mantenerlo en los rangos de $11-15^{\circ} \mathrm{C}$ y $35-40 \%$ de humedad relativa para materiales de blanco y negro. Posteriormente se deben separar materiales como nitrocelulosade otros y hacer pruebas para asegurarse que no los dañen las envolturas u otros materiales con los cuales están en contacto directo las fotografías. Para las acciones subsecuentes de conservación (limpieza, estabilización, restauración, separación por procesos y formatos, establecimiento de microclimas, etcétera), hay que basarse en las normas establecidas y explicadas en manuales reconocidos. Pero siempre hay que estar informados acerca de nuevos conocimientos: también los manuales pueden caducar.

\section{Propuesta 3:}

\section{C atalogación de primer nivel. C ampos fundamentales para la cataloga- ción de fotografías}

En lo que se refiere a la catalogación de las fotografías pongo a discusión un esquema con los campos fundamentales basados en el formato MARC21 para garantizar el intercambio. Cada fototeca podrá añadir los campos que considere pertinentes. 
El patrimonio fotográfico de México: una responsabilidad para los... 103

Campos basados en MARC21 y su aprovechamiento:

\begin{tabular}{|l|l|l|}
\hline 040 & FUENTE DE CATALOGACIÓN & $\begin{array}{l}\text { Fototeca o entidad a la cual está adscrita la foto- } \\
\text { teca, si se trata de catalogación original. }\end{array}$ \\
\hline $100 / 10$ & $\begin{array}{l}\text { AUTOR PERSO NAL / } \\
\text { CORPORATIVO }\end{array}$ & Fotógrafo / Institución \\
\hline 240 & TÍTULO UNIFO RME & Construcción normalizada por el catalogador.28 \\
\hline 245 & TÍTULO [material gráfico $]$ & Título original creado por el fotógrafo \\
\hline 260 & PIE DE IMPRENTA & $\begin{array}{l}\text { En caso de fotografía no publicada, asentar fe- } \\
\text { cha de creación. }\end{array}$ \\
\hline 300 & DESCRIPCIÓN FÍSICA & $\begin{array}{l}\text { Designación específica del material, otros deta- } \\
\text { lles físicos, color, dimensiones. }\end{array}$ \\
\hline 440 & $\begin{array}{l}\text { OTRAS CARACTERÍSTICAS FÍ- } \\
\text { SICAS D EL MATERIAL }\end{array}$ & Procesos fotográficos, soportes, etc. 29 \\
\hline 500 & TíTULO DE SERIE & $\begin{array}{l}\text { Nombre de la serie que le asignó el fotógrafo o } \\
\text { grupo documental al que pertenece la fotografía. }\end{array}$ \\
\hline 520 & NOTAS DENERALES & Flexible. \\
\hline 540 & $\begin{array}{l}\text { NOTA SOBRE DERECHO DE } \\
\text { AUTOR }\end{array}$ & $\begin{array}{l}\text { ENCABEZAMIENTOS DE } \\
\text { MATERIA } \\
\text { tado en la fotografía: personajes, objetos, luga- } \\
\text { res, acontecimientos, etc. }\end{array}$ \\
\hline 650 & Temas. \\
\hline
\end{tabular}

Para catálogos colectivos sería necesario considerar los campos de localización física y/ o electrónica, si es el caso:

\begin{tabular}{|l|l|l|}
\hline 852 & LOCALIZACIÓN & Fototeca y clave topográfica. \\
\hline 856 & ACCESO ELECTRÓ NICO & $\begin{array}{l}\text { En caso de que exista liga con un archivo gráfi- } \\
\text { co para visualizar la fotografía. }\end{array}$ \\
\hline
\end{tabular}

Para insertarnos en la discusión acerca de los nuevos paradigmas de control bibliográfico se presenta a continuación un mapeo de la propuesta con otros esquemas. Q uisiera aclarar aquí que los campos no necesariamente deben llamarse igual a los campos MARC. Lo que importa es lograr la compatibilidad sin perder la frescura de la innovación y la flexibilidad razonada.

28 En caso de retrato: el nombre de o de los retratados, lugar, fecha dela toma. En caso delugar: nombre del lugar, fecha de la toma. En caso de evento o acontecimiento: denominación del evento, lugar, fecha de la toma.

29 La Fototeca del INAH en Pachuca tradujo el listado de procesos fotográficos del International Museum of Photography. 
La catalogación de fotografías sigue siendo un problema no resuelto, una parte del cual lo constituye la definición de los elementos indispensables para hacer una descripción adecuada que permita que la información sea a la vez intercambiable con otras instituciones y, por ende también la construcción de catálogos colectivos. El desafío del ambiente digital desató una competencia feroz entre varios organismos para mantenerse a la vanguardia de la descripción de recursos electrónicos, lo que produjo la construcción de nuevos paradigmas de control bibliográfico basados en los lenguajes de hipertexto. El mapeo de las diferentes propuestas está a la orden del día y demuestra la necesidad de encontrar acuerdos. O tro problema radica en la diversidad de géneros de la fotografía misma. Un paso gigantesco lo ha dado la Visual Resources Association en su más reciente versión de los CoreCategriæ $\$^{0} \mathrm{con}$ el simple añadido de un campo (tipo de registro), que define si la fotografía que se registra es una obra en sí o una imagen; es decir, una representación visual de una obra determinada, lo que permite ocupar los mismos campos de descripción para ambos tipos de fotografía (creación original/ reproducción-sustituto de una creación original), que tanta polémica ha causado. Pero no debemos negar la importancia del formato MARC - basado en una experiencia acumulada indiscutible y que domina el mundo de las bases de datos y las hace compatibles- y la normalización que ofrecen las Reglas de Catalogación Angloamericanas.

Campos fundamentales de diferentes esquemas (mapeo):

\begin{tabular}{|l|l|l|}
\hline VRA CORE CATEGORIES 3.0 & DUBLIN CORE & MARC 21 \\
\hline TIPO DE REGISTRO & & \\
\hline TIPO & TIPO & [Material gráfico] \\
\hline TÍTULO & TÍTULO & $240 / 245 / 440$ \\
\hline $\begin{array}{l}\text { MEDIDAS } \\
\text { MATERIAL } \\
\text { TÉCNICA }\end{array}$ & FORMATO & $300 / 340$ \\
\hline CREAD OR & CREAD OR & $100 / 10$ \\
\hline FECHA & FECHA & 260 \\
\hline TEMAS & TEMA & 650 \\
\hline RELACIÓN & RELACIÓN & 500 \\
\hline DESCRIPCIÓN & DESCRIPCIÓN & 520 \\
\hline FUENTE & FUENTE & 040 \\
\hline DERECHOS & DERECHOS & 540 \\
\hline & & 500 (flexible) \\
\hline
\end{tabular}

30 Visual Resources Association, VRA CoreCategries vesion3.0, consultado en http/ / unwdbedineed/ 
Para catálogos colectivos, sería necesario considerar los campos de localización física y/ o electrónica, si es el caso:

\begin{tabular}{|l|l|l|}
\hline UBICACIÓN & & 852 / 856 \\
\hline NÚM. DE IDENTIFICACIÓN & IDENTIFICADOR & 852 \\
\hline
\end{tabular}

\section{Propuesta 4: \\ Descripción del contenido pictórico}

Aparte de los vocabularios controlados que permiten reducir y normalizar las "mil palabras" que dicen las imágenes, nos parece interesante tomar en cuenta (no solamente para la descripción de reproducciones fotográficas de obras artísticas) la descripción iconográfica y sus niveles, como lo propone Erwin Panofsky31 porque ofrece un marco intelectual para leer una fotografía en toda su complejidad:

1) Análisis pre-iconográfico, que describeo bjetos, sujetos, acontecimientos y sus propiedades basándose en la experiencia cotidiana y la cultura general.

2) Análisis iconográfico, que idanificaimágenes, historias, alegorías, etcétera basándose en conocimientos de los temas y formas artísticas.

3) Análisis iconológico, que intepretaprincipios socioculturales subyacentes basándose en conocimientos acerca de la sociedad y la cultura de la época.

\section{BIBLIOG RAFÍA}

\section{Fotografia}

Baldwin, G ordon, Lodkingat photogaphs A giidetotehnical tems Malibu: The J. Paul G etty Institute-British Museum Press, 1991, 88 pp.

Barthes, Roland, Lacámaralúida. Nctasdbrelafotografía, Barcelona: Paidós, 5a. ed., 1997, 207 pp.

Bourdieu, Pierre, Photography: amiddebrowart, Stanford: Stanford University, 1990, 218 pp.

Fontcuberta, Joan, Fotografía: conceptosyproedimientos, Barcelona: Editorial Gustavo Gili, 1990, 204 p.

Freund, G isèle, Lafotografíacomodbamentosoaial, Barcelona: Editorial G ustavo Gili, 1983, 207 pp.

D ubois, Philippe, El actofotogáfica Delarepresentaciónalareexpión Barcelona: Editorial Paidós, 2a. ed., 1994, 191 pp.

31 Cfr. García Marco, Francisco Javiery María del Carmen Agustín Lacruz, "El análisis de contenido de las reproducciones fotográficas de obras artísticas", en Valle Gastaminza, qp at,, p. 154. 
Keim, Jean A., Historia de la fotogafía, Barcelona: Editorial Oikos-Tau, 1971, 125 pp.

Melara, Miriella, "Lafotografíay otras amenazas alas tradiciones artísticas y literarias del siglo XIX en Francia", en Diớgenes núm. 162, México, 1996, pp. 41-59.

\section{F otógrafos y archivos fotográficos mexicanos}

Alquimia Orgamodd SistemaNacional deFototecas México: CNCA-INAH (publicación periódica)

Bali, Jaime y Víctor Hugo Valencia, "A cervos fotográficos. Imágenes de la historia, historia de la fotografía. Sistema Nacional de Fototecas", en México en e Tiempo Revista de Histaria y Conservacón núm. 2, México, 1994, pp. 45-50.

Casanova, Rosa, "Ingenioso descubrimiento. A puntes sobre los primeros años de la fotografía en México", en Alquima, año 2, núm. 6, México, mayo-agosto de 1999, pp. 7-14.

Casanova, Rosa, "Un sistema nacional de la fotografía”, en Alquimia, año 1, núm. 2, México, enero-abril de 1998, p. 41.

D avidson, Martha et al. (eds.) Picurecolletions, Mexica A giidetopicuresarrcesintheUnitedMexicanStates, Metuchen, New Jersey: Scarecrow, 1988, $292 \mathrm{pp}$.

D ebroise, O livier, Fugamexicana Unreemidoporla fotogafíaenMéxic, Mé xico: Consejo Nacional para la Cultura y las Artes (CNCA), 1998, 393 pp.

"Fotografía", en EnidqpeediadeMéxica tomo IV, México: Enciclopedia de México, 1978, pp. 758-782.

Monroy Nasr, Rebeca, "Lafotografía mexicana ayer y hoy", en Méxicoend Tiempo ReistadeHistaiayCanservacón, núm. 31, México, 1999, pp. 1823.

Musacchio, Humberto, "Fotografía”, en DicionanioEnaddpédicodeMéxic Ilustrado, vol. II, México: Edotorial A. León, 1989, pp. 653-657.

Naggar, Carole y Fred Ritchin, Méxica Thraughforigneged Vistopargiosextranjerss 1850-1990, New Y ork: W.W. Norton, 1993, 320 pp.

Yanes, Emma, "La voluntad de mirar", en Méxicoend Tiempa Reista de HistariayConservacoón núm. 31, México, 1999, pp. 10-17. 


\section{N ormalización de colecciones visuales}

Archivo G eneral de la Nación, D epartamento de Restauración, Conservaaónyrestauracoóndecdecionesfotogáficas, México: AGN, s.f. 29 pp. (traducción de un texto de Eugene O stroff, Smithonian Institute)

Art Libraries Society of North America (ARLIS/ NA) and Visual Resources Association (VRA), Criteioparalacontrataiónyretenióndeprofesionalesde rearsosvisuales, 19 de febrero de 1998, consultado en http/ / utwwarlisna.arg publications/ citeriasphtm.

Barra Moulain, Paula Alicia e Ignacio Gutiérrez Ruvalcaba, Nomascatalo gáficas dd Sistema Nacional deFototecas dd INAH (manual ténico), México: INAH, 2000, (Colección Alquimia)

Besser, Roland, "The changing role of photographic collections with the advent of digitization", en Katherine Jones-G armil (ed.) Thewined msam Washington: American Association of Museums, 1997, consultado en http/ / urwwgeisuda.edl/ hovard/ Papes/ gamil-astmanhtm

Besser, Howard, "Image standards needed", ponencia presentadaal Napa CIM Meding consultado en

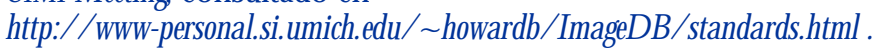

Copyight and fair use thegreatimagedbbate, editado por Robert A. Baron, en Visual Resarces vol. 12, núm. 3-4, 1997, pp. $233 f f$.

Create aproeduremanual for catalogingphotographs, Tucson, A rizona: University of Arizona, Center for Creative Photography, [1991?], 97 pp.

Childress, Eric et al. (comps.), Sedetedresarcesforimagerdatedintellectual contrd standards, originalmente publicado en VRA Bulletin, vol. 23, núm. 4, invierno de 1996, consultado en

http/ / unurdoedinedu/ art/ vel dr.htm .

Day, Michael, Metadata Mappingbetweenmtadata fomats, UK O LN: The UK O ffice for Library and Information Networking, University of Bath, United Kingdom, consultado en http/ / ukdnacuk/ mtadata/ interperability/ .

Eastman Kodak Company, Conservationofphotographs Rochester: Eastman Kodak Company, 1985, 156 pp.

Escamilla G onzález, G loria, Lista deencabezamientos demateia/ daboradaen \& Departameto decatalogaión dela Biblicteca Naaional deMéxico, México: UNAM, Instituto de Investigaciones Bibliográficas, 1978, 876 pp. 
Flynn, Marcy and HelenaZinkham, "TheMARC format and electronic reference images: experiences from the Library of Congress Prints and Photographs Division", en Visual Resarres vol. XI, núm. 1, 1995, pp. 63-65.

G arcía Aguilar, María Idalia, "Legislar para preservar el patrimonio documental mexicano: un reto para el nuevo milenio", en InvestigacónBiblio teedógica, vol. 14, núm. 28, México, enero-junio de 2000, pp. 97-114.

G arcía Caballero y Eva María Méndez Rodríguez, "Nuevas tecnologías y servicios de información gráfica; reflexiones para el profesional de la información ante la digitalización de imágenes fijas", ponencia presentada en las VIJomadasEspañdasdeDoumetacoón FESABID 98, consultado en http/ / unwiflorida-uni.@/ fesabid98/ commicaiones/r_garáa/ r_garáahtm

G arduño Vera, Roberto, Moddobibliogáficobasadbenfomatosdeintercambioy en nomas intemaaconales ciettadb al contrd bibliogáfico univesal, México: UNAM, Centro Universitario de Investigaciones Bibliotecológicas, 1996, 220 pp. (Monografías, 19)

Garduño Vera, Roberto, "Paradigmas normativos para la organización documental en los albores del siglo XXI", en InvestigacónBiblictecoógica, vol. 14, núm. 28, México, enero-junio de 2000, pp. 115-149.

Getty Art History Information Program, Art and ArditectureThesaunus, New Y ork: Oxford University Press, 2a. ed., 1994, consultado en http/ / unw.gï.getty.edv/ gi// aathhm .

Getty Art History Information Program, Categries for the Desciption of Works ofArt (CDWA), consultado en http// unwahipgetty.edu/ gi// colwa .

G ill, Tony and Catherine G rout and Louise Smith, V isual arts, msamsand altural heitageinformation standards A domain-speificreviewof rederant standards for networkedinformation discovey, marzo de 1997, consultado en http/ / vadsahosncuk/ training advicel standardd/ standardshtm.

Guinchat, Clairey Michel Menou, Introducióngeneal alasaienaiasyténicasde la infomadón y doumetacoón (segunda edición corregida y aumentada por Marie-France Blanquet), Madrid: CIND OC(CSIC)/ UNESCO, 1990, $551 \mathrm{pp}$.

Harrison, Helen P., Pidurelibranianship, Phoenix, AZ: O ryx Press, 1981, $542 \mathrm{pp}$.

IBCON, Directaro de centros de informadón México: IBCON (publicación anual). 
ICONCLASS Research \& D evelopment Group (IRD G), ICONCLASS Bronser, Utrecht: Utrecht University, 1992, 1994 (en diskette), consultado en http:/ / icondassletnunnl.

Image Permanence Institute (IPI), Rochester: Rochester Institute of Technology, consultado en http// / ununit.edl/ 661unw1.

Irvine, Betty Jo (ed.), Art Libraries Society of North America, Faalities standardsforartlibraniesandvisual resarcescdletions, Englewood: Libraries Unlimited, 1991, $216 \mathrm{pp}$.

ISBD (NBM): Descipiónbibliogáíicaintemacional nomalizada para materialesno libranios, Madrid: ANABAD, Arco Libros, 1993, 122 pp.

International Organization for Standarization (ISO), consultado en http/ / unwisach

International Organization for Standarization/ International Electrotechnical Commission Joint Technical Committee (ISO / IEC JTC1), consultado en http// / unwwjtcl.org .

International O rganization for Standarization/ Technical Committee 42 Photography (ISO / TC42), consultado en http:/ / www.pima.net/ standards/ tc42.htm.

Köppen, Elke, Aspetosnomativosen cleciones visuales un estudiocomparativo defotcteas mexicanas, Tesis de Maestría en Bibliotecología, México: Facultad de Filosofía y Letras, UNAM, 2001, 138 pp.

Leja, Ilya, Todigitizeornot todiggize Issuesforimagebased clletions, Information Technology Column, mayo de 1998, consultado en http/ / mag.cond mmidid/ it98may.htm

"Ley Federal del D erecho de Autor, publicada en el Diario Oficial de la Federación el día 24 de diciembre de 1996. Modificada por decreto publicado el 19 de mayo de 1997" , en LegesycódigosdeMéxica Legisacónso bredaechosdeautor, México, Editorial Porrúa, 1999, pp. 9-84.

Memoryof theworld. Safeegrardingthedboumentaryheitage A guidetostandards, re commended pradicesandrefereneliteraturerdated tothepreservation of douments of all kinds prepared by the International Advisory Committee for the UNESCO Memory of the World Programme, Sub-Committee on Technology for the G eneral Information Programme and UNISIST, United Nationas Educational, Scientific and Cultural Organization, s.f., consultado en http/ / wuwrunescaarg webwodd/ modm/ administ/ e/ gridd gridkochtm 
Network D evelopment and MARC Standards O ffice, Library of Congress, DublinCare MARC/ GILScrosswalk, noviembre de 1999, consultado en http/ / lonelagov/ mard dacoosshtm.

Noma Intemaaional Geneal deDescripión Ardivística ISAD(G), México: Archivo G eneral de la Nación, 1997, 43 pp. (Cuadernos del Archivista)

O sorio Alarcón, Fernando, Lafotdecaenlosmuses, México: UNAM, Centro de Investigación y Servicios Museológicos, Coordinación de D ifusión Cultural, 1990, $51 \mathrm{pp}$.

Pacey, Philip, "Information technology and the universal availability of images", en IFLA Jaumal, vol. 9, núm. 3, 1983, pp. 230-233.

Parker-Betz, Elisabeth (ed.), Graphic materials: Rules for describing orignal items and historical colletions, Washington, D.C.: Library of Congress, 1982. Versión electrónica actualizada consultada en http/ / unwiloc.gov/ n/ print/ gor/ graphmat.htm

Photographic and Imaging Manufactures Association (PIMA), consultado en http/ / unwpimand/ standards TC.htm.

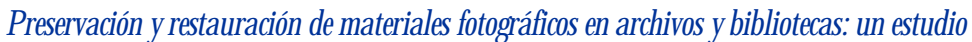
di RAMP condretrices estudio preparado por Klaus B. Hendricks, París: Programa General de Información UNISIST, Unesco, 1984, 87 pp.

Reejasdecatalocaaiónangoameicanas, México: UNAM, Instituto de Investigaciones Bibliográficas, 2a. ed. rev. de 1998, con modificaciones de 1993, 1995, 824 pp.

Ritzenthaler, Mary Lynn; Munoff, G erald J. y Margery S. Long, Archives andmanuscipts Administration of Photographicodlections, Chicago: Society of American Archivists, 1984, 173 pp.

Schuller, Nancy Shelby, Management for visual resarces odlections, Englewood, Colorado: Libraries Unlimited, 2a. ed., 1989, 169 pp.

Sutcliffe, G lyn, Slide colletion management in libraries and informations units, Hampshire and Vermont: G ower, 1995, 219 pp.

ThesaunusforgaphicmateialsI. Subjettems(TGMI), compiled by Prints and Photographs Division, Library of Congress, consultado en http/ / loweblocgo/ m/ pint/ tgml.

Thesaunus for graphic mateials II. Genreand dharaderistics headings (TGM II), compiled by Prints and Photographs Division, Library of Congress, consultado en http/ / loweblocgov/ m/ print/ tgm2. 
Trant, Jennifer, "Framing the picture: Standards for imaging systems", ponencia presentada en la Intemational ConferenceonHypemeedia and Inte radivityinMuseums MuseumComputerNeworkJaintConferenee San D iego, California, octubre de1995, consultado en http/ / urwardimisecom/ papes/ jtichim/ idim1.introhtm.

Valdez Marín, Juan Carlos, Manual deconøevacoónfotogáfica Guía deidantificaión, estabilizaaónyrestauracoóndeprocesosfotogáficosdelossigosXIX yXX, México: INAH, 1997, 146 pp. (Colección Alquimia)

Valle Gastaminza, Félix del (ed.), Manual dedbamentaión fotogáfica, Madrid: Editorial Síntesis, 1999, 255 pp. (Biblioteconomía y D ocumentación).

Van de Waal, ICONCLASS. An iconographic dassification system completed and edited by L.D . Couprie, R.H. Fuchs, E. Tholen, et al., Amsterdam: Köninklijke Nederlandse Akademie van Wetenschappen, 1973-1985, 17 vols.

Visual Resources A ssociation, VRA crecateggres, vesion3.0, consultado en http/ / uruuvra.dbedineelu.
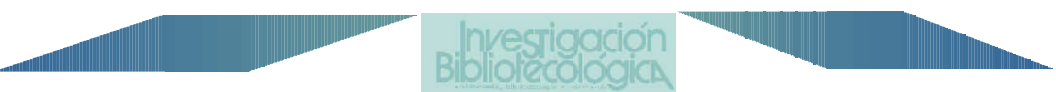